\title{
Wideband Planar Antenna for New Generation Mobile Applications
}

\author{
P. C. Bybi, B. Jitha, P. Mohanan, and C. K. Aanandan \\ Received 12 October 2006; Revised 25 January 2007; Accepted 26 March 2007 \\ Recommended by James Becker \\ A wideband, compact planar monopole antenna having a $2: 1$ VSWR bandwidth of $98 \%(1.68 \mathrm{GHz}-4.9 \mathrm{GHz})$ is presented. The \\ omnidirectional radiation pattern with moderate gain and linear polarization in the entire band makes the antenna an excellent \\ candidate for new generation mobile applications. Details of the antenna design and a comparison of simulated and measured \\ results are presented and discussed.
}

Copyright (c) 2007 P. C. Bybi et al. This is an open access article distributed under the Creative Commons Attribution License, which permits unrestricted use, distribution, and reproduction in any medium, provided the original work is properly cited.

\section{INTRODUCTION}

With the development of wireless communications, there is a growing demand for both voice and data services. The service providers are upgrading their networks with advanced technologies since the number of mobile phone subscribers, as well as usage rate, is growing tremendously. Recently, FCC licensed a spectrum designated "Advanced Wireless Services" (AWS) that offers a variety of wireless services including the broadband $3 \mathrm{G}$ mobile. Leading mobile telephone manufacturers are integrating features like satellite radio and TV to the hand-held devices. These systems need an antenna with wideband or multiband characteristics to cater the forthcoming mobile communication.

One technique to provide such feature is to integrate a multiband antenna that operates over specific narrowband frequencies such as broadband dual-frequency meandered CPW-fed monopole antenna [1], planar monopole antenna for GSM/DCS/PCS/WLAN operation band [2], a low profile monopole antenna for GSM/DCS/PCS/UMTS operation [3]. However, it would be extremely difficult to accurately achieve the frequency requirements of all future communication systems. Alternately, a single antenna that covers a wide range of frequencies with the same polarization would be an ideal candidate not only for present multiband applications but also for future communication systems.

Recently many antennas with wideband characteristics have been successfully designed for mobile applications [4-8]. For example, a compact wideband planar antenna is reported [4] which covers $(870 \mathrm{MHz}-2450 \mathrm{MHz})$ including GSM/GPS/DCS/PCS/UMTS and WLAN applications. It uses " $M$ "-like radiating element with a main ground below the microstrip feed and a " $T$ " -shaped ground protruding from the main ground below the radiating element. A CPW-fed wideband planar monopole antenna $(1710 \mathrm{MHz}-$ $2483 \mathrm{MHz}$ ) for operations in DCS, PCS, 3G, and Bluetooth [5] uses the symmetric slope in the ground plane to obtain wideband performance. Wideband monopole antenna $(1700 \mathrm{MHz}-2500 \mathrm{MHz})$ with a parasitic square ring patch that is shorted to the ground and fed by top loaded coaxial probe is reported [6]. Folded monopole antennas are widely used for broadband application. For example, a CPWfed broadband G-Shaped monopole antenna for wireless applications is reported by Kim et al., which incorporate two folded monopoles to get a broad bandwidth [7] and a folded monopole antenna suitable for DCS/PCS/UMTS/WLAN operation is reported by Lee et al. [8].

In this paper, we report a compact, wideband, printed, funnel-shaped monopole antenna that operates from $1.68 \mathrm{GHz}$ to $4.9 \mathrm{GHz}$, covering major wireless communication bands like AWS, DCS, DECT, PCS, PHS, 3G, UMTS, DSR, Wi.Bro, ISM, and DMB.

\section{DESCRIPTION OF THE PROPOSED ANTENNA}

The geometry and dimension of the proposed antenna is illustrated in Figure 1. The proposed antenna comprises of a $50 \Omega$ microstrip line feed, strip monopole of length $L_{M}=$ $0.164 \lambda(15 \mathrm{~mm})$ and width $W_{M}=3 \mathrm{~mm}$ (same as the width of $50 \Omega$ microstrip line) with a funnel-shaped patch $F_{1}$ and a similar patch $F_{2}$ electromagnetically coupled to the monopole on the other side of the substrate. The antenna is 


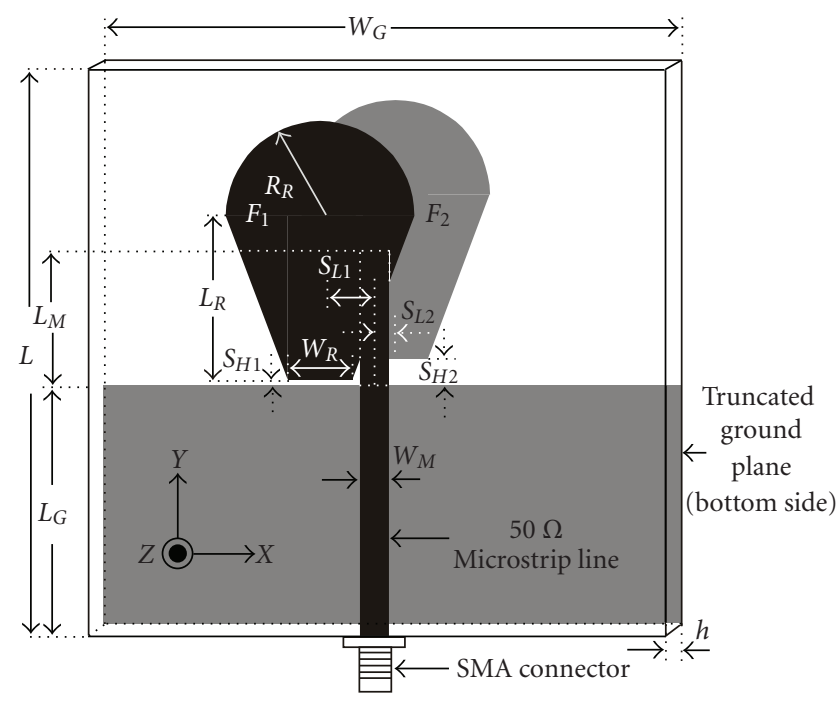

Figure 1: Geometry and optimized dimensions of the proposed antenna $\left[L=67, W_{G}=67, L_{G}=29, L_{M}=15, W_{M}=3, W_{R}=7.5\right.$, $L_{R}=19, R_{R}=11, S_{H 1}=0.3, S_{L 1}=6.5, S_{H 2}=3, S_{L 2}=5.25, h=1.6$ (units in $\mathrm{mm}$ ), $\left.\varepsilon_{r}=4.4\right]$.

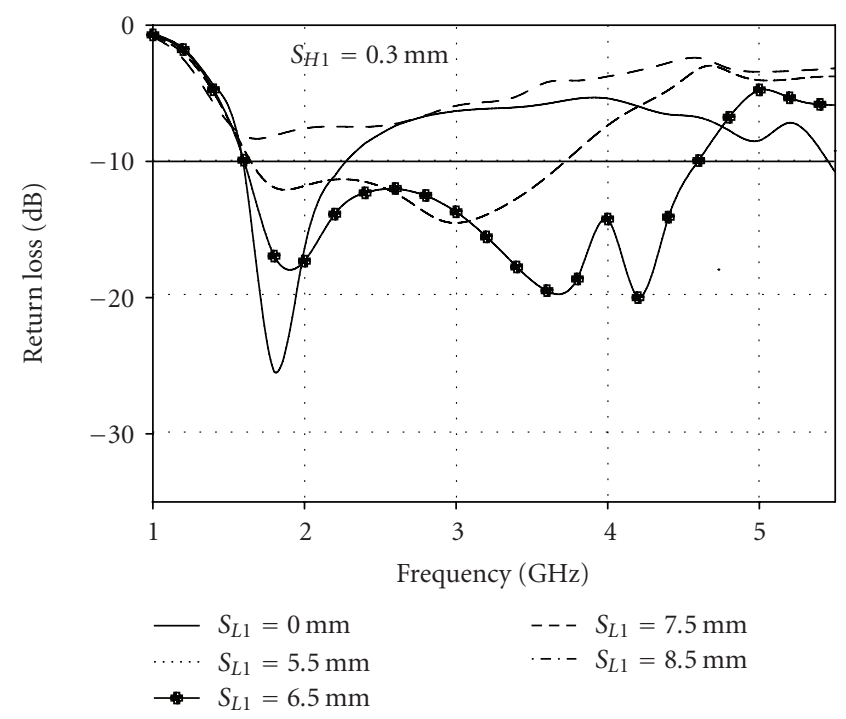

FIgURE 2: Effect of position of patch $F_{1}$ on return loss characteristics $\left[L=67, W_{G}=67, L_{G}=29, L_{M}=15, W_{M}=3, W_{R}=7.5, L_{R}=19\right.$, $R_{R}=11, S_{H 1}=0.3, h=1.6$ (units in $\mathrm{mm}$ ), $\varepsilon_{r}=4.4$ ].

etched on a substrate of relative permittivity $\varepsilon_{r}=4.4$ and thickness $h=1.6 \mathrm{~mm}$. The radiating patches have a base width $W_{R}=0.082 \lambda(7.5 \mathrm{~mm})$, length $L_{R}=0.208 \lambda(19 \mathrm{~mm})$, and the radius of curvature $R_{R}=0.121 \lambda(11 \mathrm{~mm})$, where $\lambda$ is the free space wave length corresponding to the mean frequency $\left(f_{c}\right)$ in the band.

From simulation studies, it is found that slight offset of patch $F_{1}$ is required for optimum bandwidth. Patch $F_{1}$ placed symmetrically over the strip monopole offered low

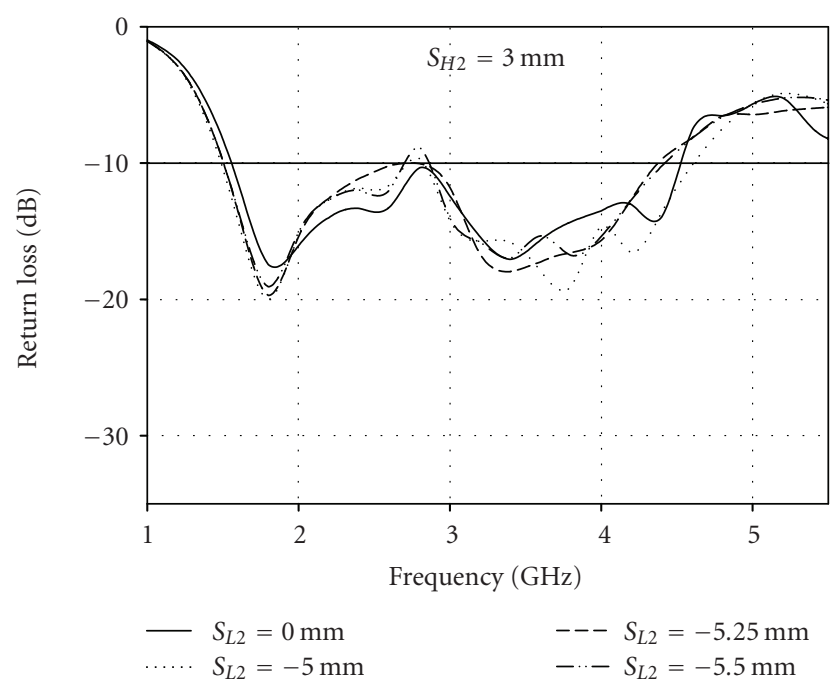

(a) $F_{2}$ offset in the same direction as $F_{1}$

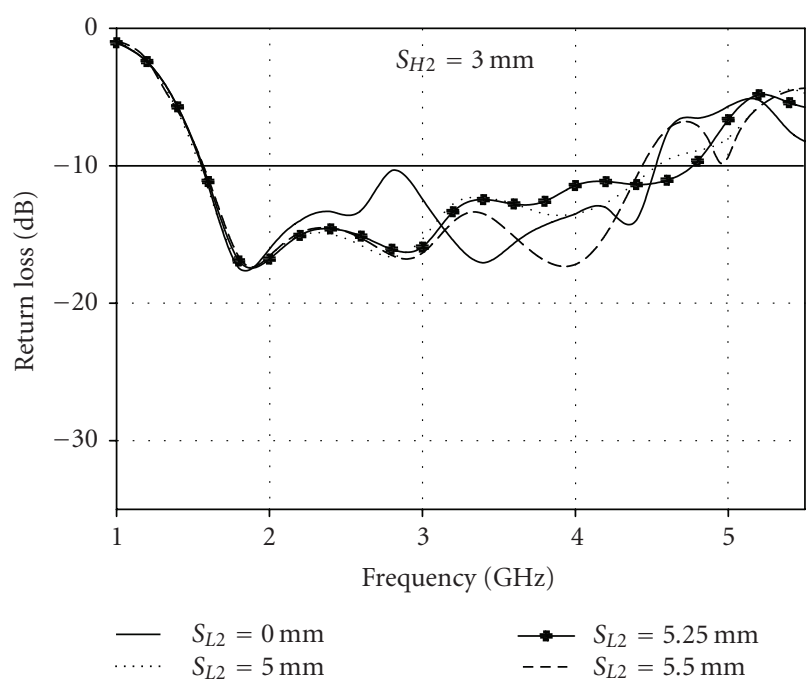

(b) $F_{2}$ offset in the opposite direction to $F_{1}$

FIGURE 3: Effect of position of patch $F_{2}$ on return loss characteristics $\left[L=67, W_{G}=67, L_{G}=29, L_{M}=15, W_{M}=3, W_{R}=7.5, L_{R}=19\right.$, $R_{R}=11, S_{H 1}=0.3, S_{L 1}=6.5, S_{H 2}=3, h=1.6$ (units in mm), $\left.\varepsilon_{r}=4.4\right]$.

impedance bandwidth. From the exhaustive simulations of the offset parameters $S_{H 1}$ and $S_{L 1}$, the optimum position of $F_{1}$ was identified. For the present design, the optimum offset parameters are $S_{H 1}=0.003 \lambda(0.3 \mathrm{~mm})$ and $S_{L 1}=0.071 \lambda$ $(6.5 \mathrm{~mm})$. This optimum behavior of the antenna is illustrated in Figure 2.

A similar patch $F_{2}$ introduced to this optimized configuration offered a much improved overall bandwidth performance. It is clear from Figure 3 that the optimum bandwidth is obtained when $S_{H_{2}}=0.033 \lambda(3 \mathrm{~mm})$ and $S_{L 2}=0.057 \lambda$ $(5.25 \mathrm{~mm})$, with $F_{2}$ offset in the direction opposite to that of $F_{1}$. 


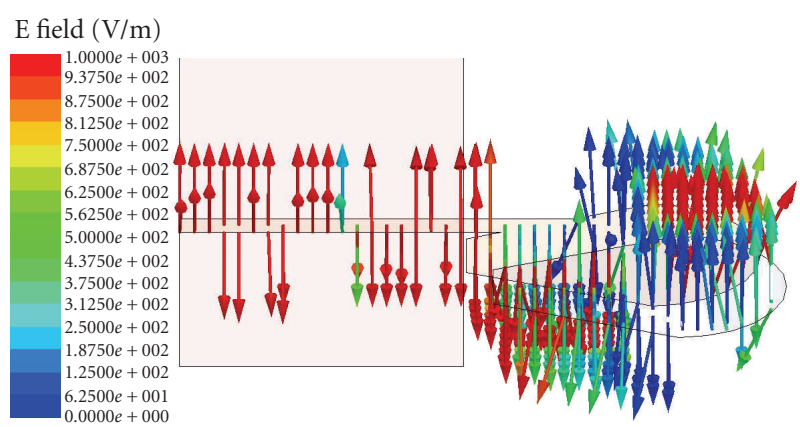

(a)

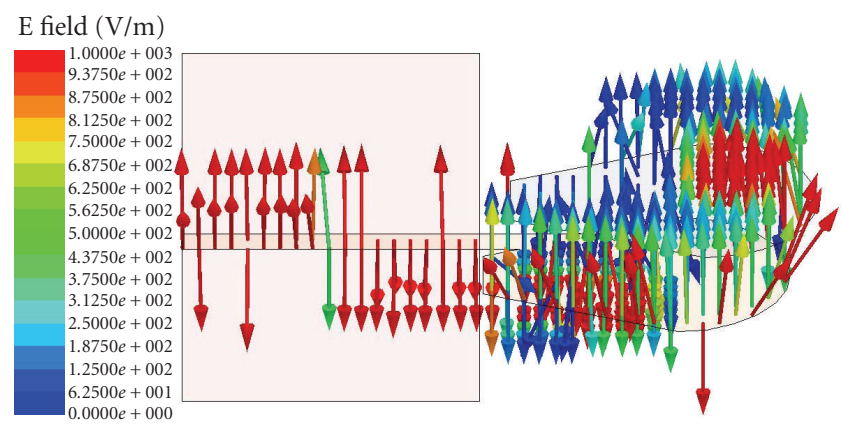

(b)

FIGURE 4: Electric field distribution in the antenna at center frequency: (a) patch $F_{2}$ in the same direction as patch $F_{1}$, (b) patch $F_{2}$ in the opposite direction to $F_{1}\left[L=67, W_{G}=67, L_{G}=29, L_{M}=15\right.$, $W_{M}=3, W_{R}=7.5, L_{R}=19, R_{R}=11, S_{H 1}=0.3, S_{L 1}=6.5, S_{H 2}=3$, $S_{L 2}=5.25, h=1.6$ (units in $\mathrm{mm}$ ), $\varepsilon_{r}=4.4$ ].

Moreover, under this condition the excited field distribution is in such a way that more fringing electric field is available on the periphery of the geometry and hence the radiation efficiency is more. On the other hand, if the patch $F_{2}$ is moved along the same direction as patch $F_{1}$, the electric field becomes weak along the periphery; thus reducing the fringing effect and resulting in low radiation efficiency. This is clearly demonstrated in Figures 4(a) and 4(b).

The influence of ground plane parameters on the resonance behavior is also studied and optimized for maximum bandwidth. Simulation results shown in Figure 5 reveals that the ground plane with a width of $W_{G}=0.735 \lambda(67 \mathrm{~mm})$ and length $L_{G}=0.318 \lambda(29 \mathrm{~mm})$ can provide the maximum bandwidth.

\section{RESULTS AND DISCUSSION}

The prototype of the funnel monopole antenna with optimal design was fabricated and tested. The measurement was performed using Agilent E8362B PNA series network analyzer. Figures 6(a)-6(c) show the simulated and measured return loss characteristics of the strip monopole, strip monopole with patch $F_{1}$, and the strip monopole with patch $F_{1}$ and $F_{2}$ respectively. The measurement confirms the wideband characteristic of the proposed antenna, as predicted in the simulation.

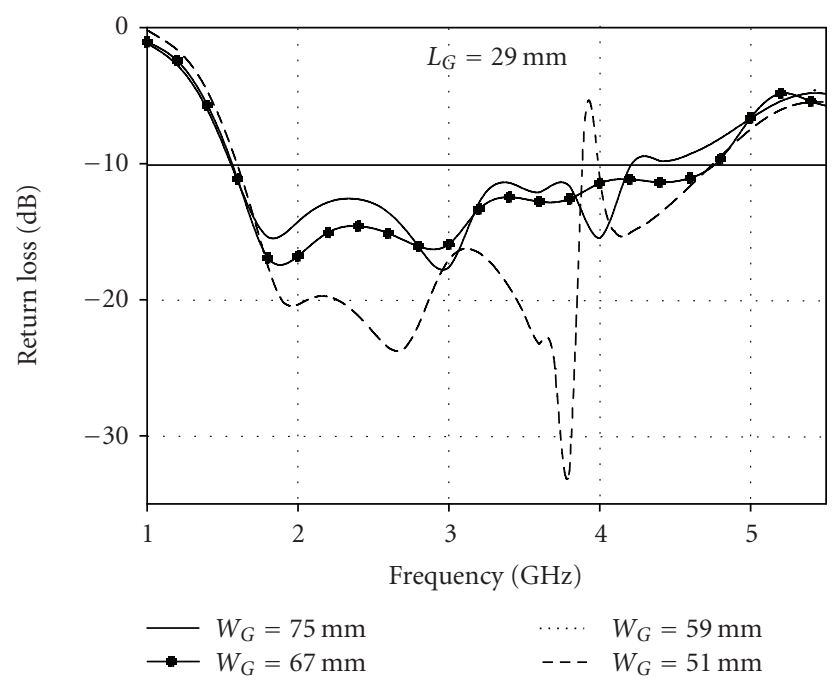

(a)

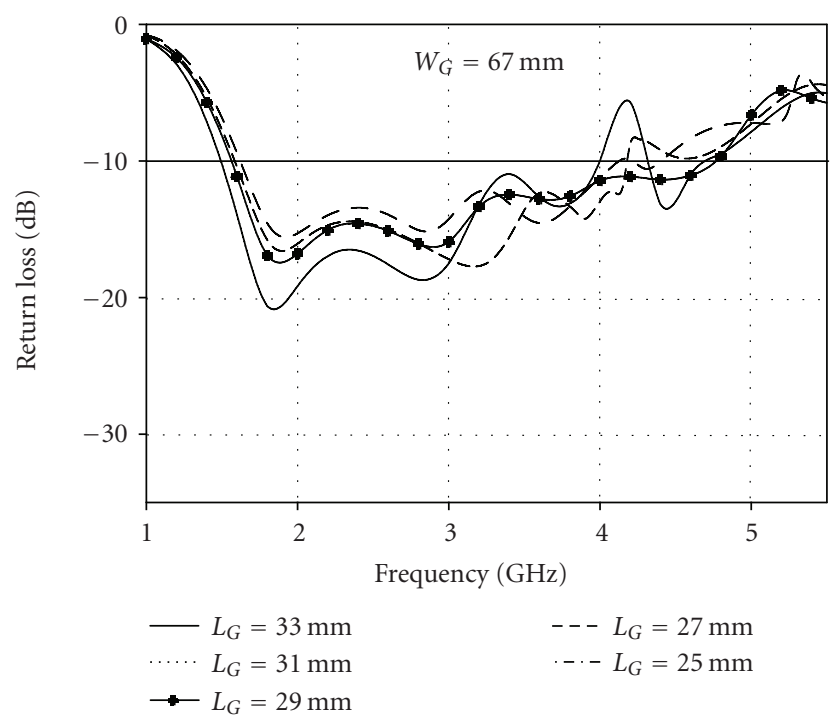

(b)

Figure 5: Effect of ground plane dimensions on the return loss characteristics: (a) $W_{G}$ variation $\left[L=67, L_{G}=29, L_{M}=15\right.$, $W_{M}=3, W_{R}=7.5, L_{R}=19, R_{R}=11, S_{H 1}=0.3, S_{L 1}=6.5$, $S_{H 2}=3, S_{L 2}=5.25, h=1.6$ (Units in mm), $\varepsilon_{r}=4.4$ ], (b) $L_{G}$ variation $\left[L=67, W_{G}=67, L_{M}=15, W_{M}=3, W_{R}=7.5, L_{R}=19\right.$, $R_{R}=11, S_{H 1}=0.3, S_{L 1}=6.5, S_{H 2}=3, S_{L 2}=5.25, h=1.6$ (units in $\left.\mathrm{mm}), \varepsilon_{r}=4.4\right]$.

The strip monopole with the truncated ground plane resonates at $2.9 \mathrm{GHz}$ with a $2: 1$ VSWR band width of $34.8 \%$. It is clear from Figures 6(b) and 6(c) that the influence of the patch $F_{2}$ is predominant at the low-frequency region (around $2.5 \mathrm{GHz}$ ). The lower cutoff frequency is also lowered by the introduction of the patch $F_{2}$. It can be seen that the proposed structure exhibits a 2 : 1 VSWR band from $1.68 \mathrm{GHz}-4.9 \mathrm{GHz}$ with $98 \%$ bandwidth at mean frequency $\left(f_{c}\right)$ of $3.29 \mathrm{GHz}$, satisfying the present day requirements of communication channels. 


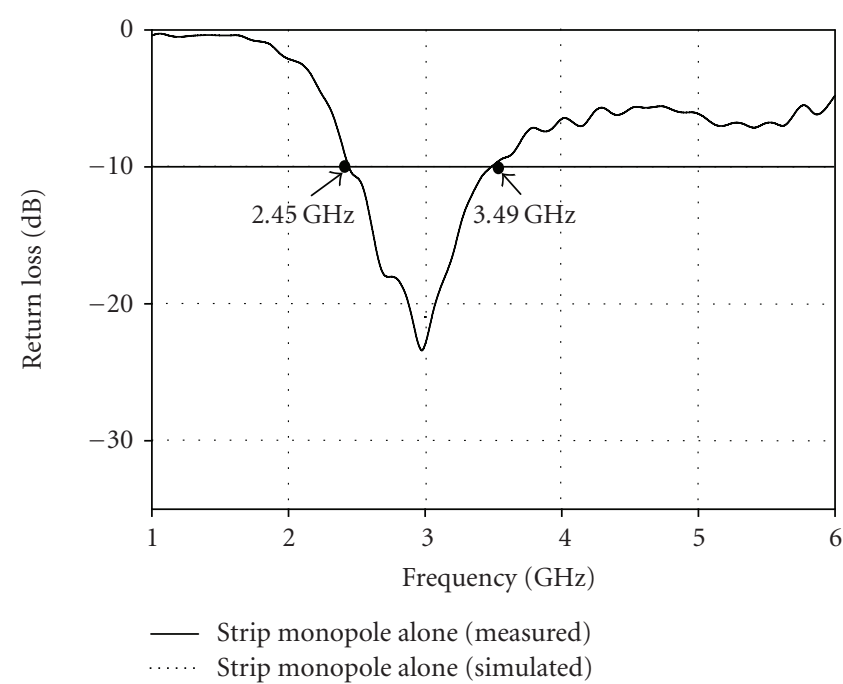

(a)

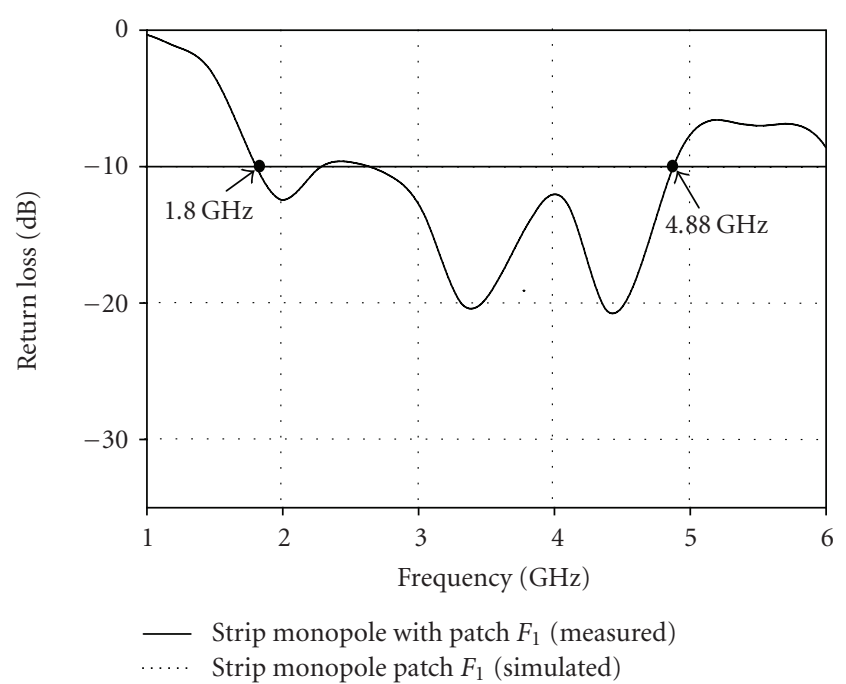

(b)

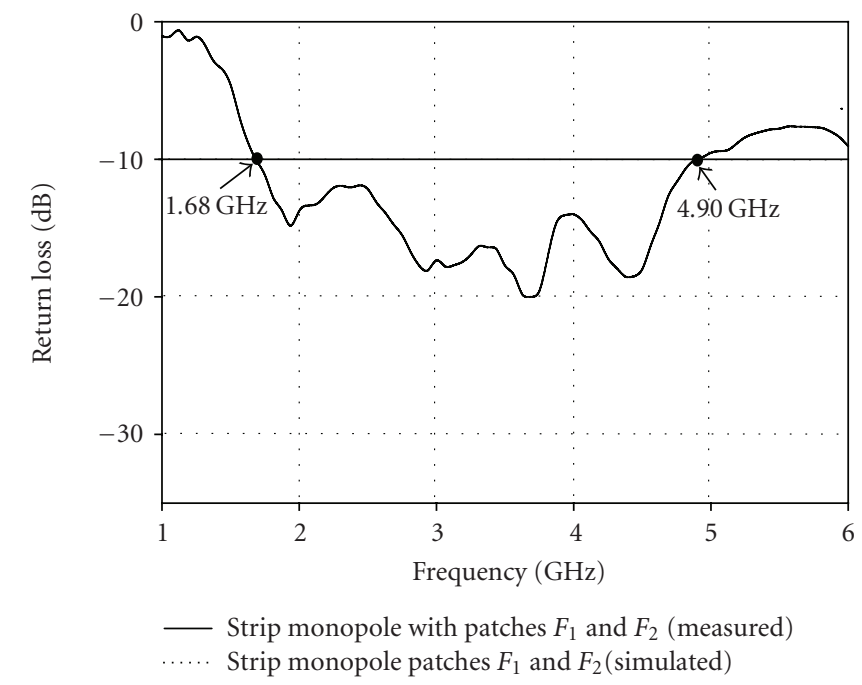

(c)

Figure 6: Measured and simulated return loss characteristics of the proposed antenna: (a) strip monopole alone $\left[L=67, W_{G}=67, L_{G}=29\right.$, $L_{M}=15, W_{M}=3, h=1.6$ (units in mm), $\left.\varepsilon_{r}=4.4\right]$, (b) strip monopole with patch $F_{1}\left[W_{R}=7.5, L_{R}=19, R_{R}=11, S_{H 1}=0.3, S_{L 1}=6.5\right.$, (units in $\mathrm{mm}$ )], (c) Strip monopole with patches $F_{1}$ and $F_{2}\left[S_{H 2}=3, S_{L 2}=5.25\right.$ (units in $\mathrm{mm}$ )].

A more insightful understanding of the proposed antenna behavior can be obtained by analyzing the current distributions at different frequencies (see Figure 7). It is evident from Figure 7(a) that at lower frequencies all the antenna elements are contributing for the radiation. In the middle frequency region (around $3.2 \mathrm{GHz}$ ) strip monopole and patch $F_{1}$ contribute strongly to the radiation, while patch $F_{2}$ improves the overall impedance matching. At the higher frequency second harmonic on the strip (Figure 6(c)) is responsible for the radiation.

Figure 8 shows the measured radiation patterns in the $X-Z$ and $Y-Z$ planes at $1.7 \mathrm{GHz}, 1.8 \mathrm{GHz}, 2.4 \mathrm{GHz}$, and
4.9 GHz, respectively. The antenna offers nearly similar radiation patterns throughout the band, except at the higherband edge. The pattern is found to be omnidirectional along the $X-Z$ plane and figure-of-eight shape in the $Y-Z$ plane. Thus the presence of funnel-shaped patches has resulted in enhancing the impedance bandwidth of single monopole antenna, without deteriorating its radiation performance. The antenna is linearly polarized along the $Y$ direction over the entire band.

The gain measurements are carried out using Agilent E8362B PNA by gain transfer method with standard antenna. Measured antenna gains in different bands, listed in 


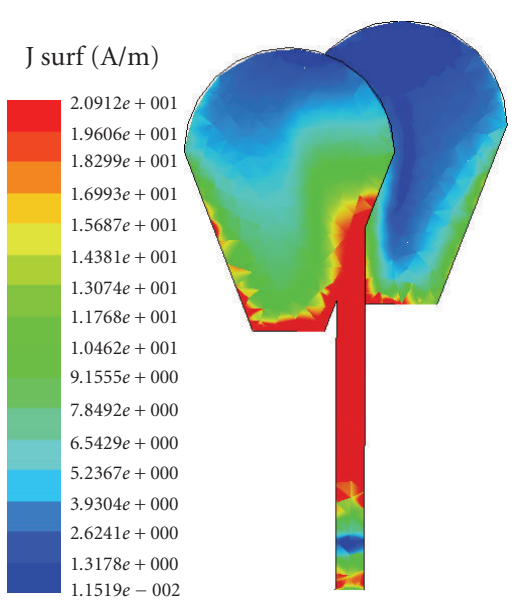

(a) $1.7 \mathrm{GHz}$

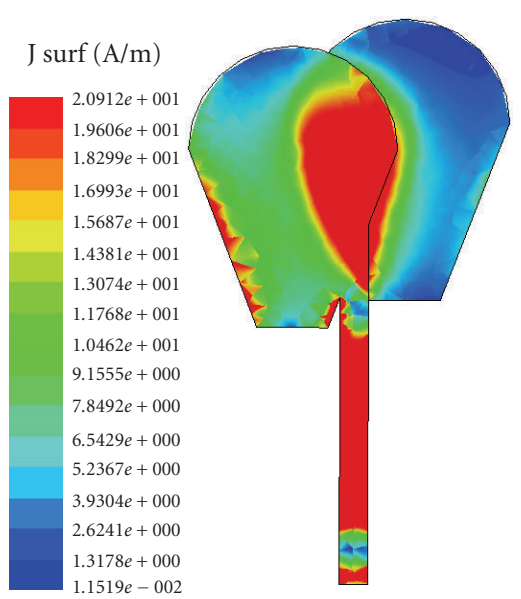

(b) $3.2 \mathrm{GHz}$

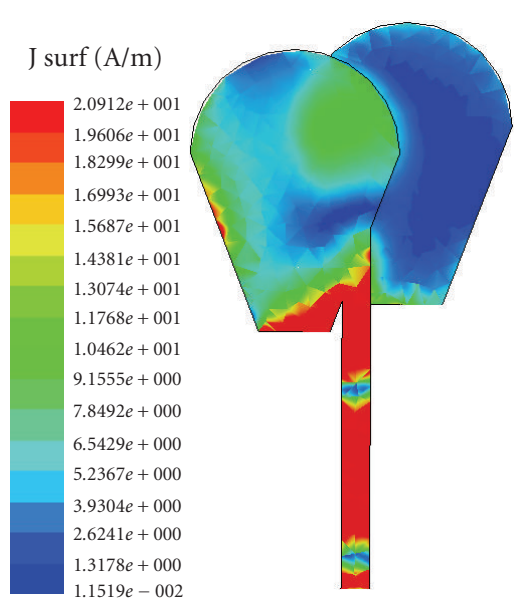

(c) $4.5 \mathrm{GHz}$

FIGURE 7: Simulated current distributions of the proposed antenna at (a) $1.7 \mathrm{GHz}$, (b) $3.2 \mathrm{GHz}$, (c) $4.5 \mathrm{GHz}\left[L=67, W_{G}=67, L_{G}=29\right.$, $L_{M}=15, W_{M}=3, W_{R}=7.5, L_{R}=19, R_{R}=11, S_{H 1}=0.3$, $S_{L 1}=6.5, S_{H 2}=3, S_{L 2}=5.25, h=1.6$ (units in $\mathrm{mm}$ ), $\varepsilon_{r}=4.4$ ].
TABLE 1: Measured gain of the proposed antenna in different bands $\left[L=67, W_{G}=67, L_{G}=29, L_{M}=15, W_{M}=3, W_{R}=7.5, L_{R}=19\right.$, $R_{R}=11, S_{H 1}=0.3, S_{L 1}=6.5, S_{H 2}=3, S_{L 2}=5.25, h=1.6$ (units in $\left.\mathrm{mm}), \varepsilon_{r}=4.4\right]$.

\begin{tabular}{l|c}
\hline Band & $\begin{array}{l}\text { Measured gain at the center } \\
\text { frequency of the band, dBi } \\
\text { (gain transfer method) }\end{array}$ \\
\hline AWS (1710-1755 MHz) & 2.7 \\
AWS (2110-2115 MHz) & 3.7 \\
DCS (1710-1880 MHz) & 4.0 \\
DECT (1880-1900 MHz) & 4.6 \\
PCS (1850-1990 MHz) & 5.3 \\
PHS (1905-1920 MHz) & 5.0 \\
3G (1920-2170 MHz) & 4.0 \\
UMTS (1920-2180 MHz) & 3.5 \\
DSR (2290-2300 MHz) & 3.1 \\
Wi.Bro (2300-2390 MHz) & 3.6 \\
ISM (2400-2485 MHz) & 4.5 \\
DMB (2605-2655 MHz) & 4.6 \\
\hline
\end{tabular}

TABLE 2: Experimental results of the proposed antenna for different center frequencies. Design values for $3 \mathrm{GHz}\left[L=73.5, W_{G}=73.5\right.$, $L_{G}=32, L_{M}=16.4, W_{M}=3, W_{R}=8.2, L_{R}=20.8, R_{R}=12$, $S_{H 1}=0.3, S_{L 1}=7.1, S_{H 2}=3.3, S_{L 2}=5.7, h=1.6$ (units in mm), $\left.\varepsilon_{r}=4.4\right]$. Design values for $4 \mathrm{GHz}\left[L=55, W_{G}=55, L_{G}=24\right.$, $L_{M}=12.3, W_{M}=3, W_{R}=6.2, L_{R}=15.6, R_{R}=9, S_{H 1}=0.23$, $S_{L 1}=5.33, S_{H 2}=2.48, S_{L 2}=4.28, h=1.6$ (units in $\mathrm{mm}$ ), $\varepsilon_{r}=4.4$ ].

\begin{tabular}{c|ccc}
\hline Designed $f_{c}(\mathrm{GHz})$ & $\begin{array}{c}f_{L}-f_{H} \\
(\mathrm{GHz})\end{array}$ & $\begin{array}{c}\text { Measured } \\
f_{c}(\mathrm{GHz})\end{array}$ & $\begin{array}{l}\text { Bandwidth } \\
(\mathrm{GHz})\end{array}$ \\
\hline 3 & $1.62-4.39$ & 3.005 & 2.77 \\
4 & $2.05-6.14$ & 4.095 & 4.09 \\
\hline
\end{tabular}

Table 1, indicate the reasonable gain offered over the entire band of operation. High gain in PCS and PHS bands is due to monopole radiation aided by current distribution on funnelshaped geometry.

The radiation efficiency of the proposed monopole antenna is determined using Wheeler Cap method [9]. The average efficiency of the antenna is found to be around $85 \%$. Antennas at center frequencies of $3 \mathrm{GHz}$ and $4 \mathrm{GHz}$ were also designed and experimentally verified as shown in Table 2.

\section{CONCLUSION}

A novel funnel-shaped monopole antenna fed by microstrip line capable of serving the needs of new generation mobile applications is proposed. Wide impedance bandwidth and omnidirectional patterns with moderate gain are the striking features of the design. 


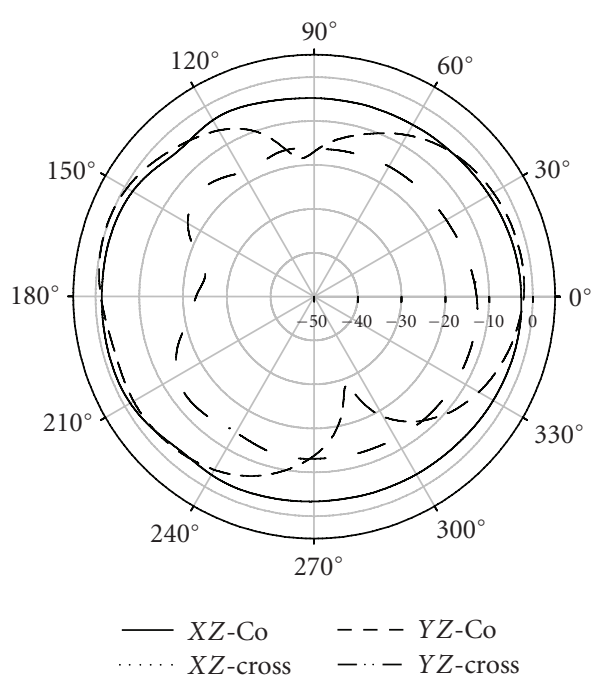

(a)

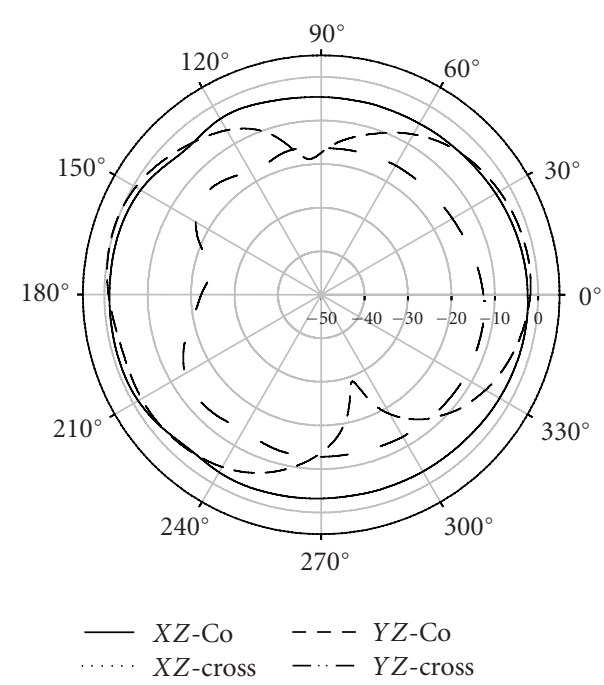

(b)

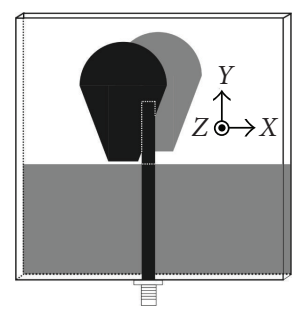

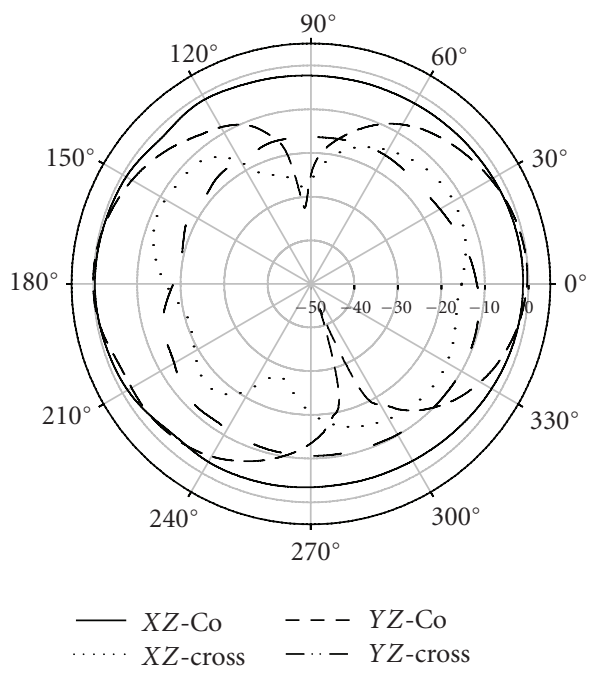

(c)

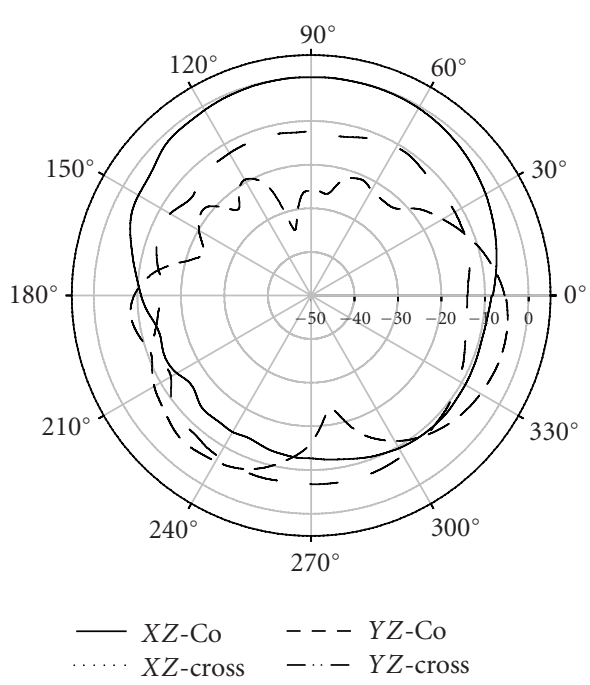

(d)

FIgURE 8: Measured radiation patterns of the proposed antenna (a) $1.7 \mathrm{GHz}$, (b) $1.8 \mathrm{GHz}$, (c) $2.4 \mathrm{GHz},(\mathrm{d}) 4.9 \mathrm{GHz}\left[L=67, W_{G}=67\right.$, $L_{G}=29, L_{M}=15, W_{M}=3, W_{R}=7.5, L_{R}=19, R_{R}=11, S_{H 1}=0.3, S_{L 1}=6.5, S_{H 2}=3, S_{L 2}=5.25, h=1.6$ (units in mm), $\left.\varepsilon_{r}=4.4\right]$. 


\section{REFERENCES}

[1] W.-C. Liu, "Broadband dual-frequency meandered CPW-fed monopole antenna," Electronics Letters, vol. 40, no. 21, pp. 1319-1320, 2004.

[2] P.-L. Teng, H.-T. Chen, and K.-L. Wong, "Multi-frequency planar monopole antenna for GSM/DCS/PCS/WLAN operation," Microwave and Optical Technology Letters, vol. 36, no. 5, pp. 350-352, 2003.

[3] K.-L. Wong, G.-Y. Lee, and T.-W. Chiou, "A low-profile planar monopole antenna for multiband operation of mobile handsets," IEEE Transactions on Antennas and Propagation, vol. 51, no. 1, pp. 121-125, 2003.

[4] Z. Du, K. Gong, and J. S. Fu, "A novel compact wide-band planar antenna for mobile handsets," IEEE Transactions on Antennas and Propagation, vol. 54, no. 2, part 2, pp. 613-619, 2006.

[5] J.-Y. Jan and T.-M. Kuo, "CPW-fed wideband planar monopole antenna for operations in DCS, PCS, 3G, and Bluetooth bands," Electronics Letters, vol. 41, no. 18, pp. 991-993, 2005.

[6] J.-S. Row and S.-H. Chen, "Wideband monopolar square-ring patch antenna," IEEE Transactions on Antennas and Propagation, vol. 54, no. 4, pp. 1335-1339, 2006.

[7] S. Kim, J. Choi, and Y. Kim, "CPW-fed broadband G-shaped monopole antenna for WLAN applications," Microwave and Optical Technology Letters, vol. 48, no. 11, pp. 2310-2311, 2006.

[8] G.-Y. Lee, S.-H. Yeh, and K.-L. Wong, "A broadband folded planar monopole antenna for mobile phones," Microwave and Optical Technology Letters, vol. 33, no. 3, pp. 165-167, 2002.

[9] H. Choo, R. Rogers, and H. Ling, "On the wheeler cap measurement of the efficiency of microstrip antennas," IEEE Transactions on Antennas and Propagation, vol. 53, no. 7, pp. 2328 2332, 2005.

\section{AUTHOR CONTACT INFORMATION}

P. C. Bybi: Department of Electronics, Centre for Research in Electromagnetics and Antennas (CREMA), Cochin University of Science and Technology, Cochin 682 022, India; bybi@cusat.ac.in

B. Jitha: Department of Electronics, Centre for Research in Electromagnetics and Antennas (CREMA), Cochin University of Science and Technology, Cochin 682 022, India;

jitha@cusat.ac.in

P. Mohanan: Department of Electronics, Centre for Research in Electromagnetics and Antennas (CREMA), Cochin University of Science and Technology, Cochin 682 022, India; drmohan@ieee.org

C. K. Aanandan: Department of Electronics, Centre for Research in Electromagnetics and Antennas (CREMA), Cochin University of Science and Technology, Cochin 682 022, India;

anand@cusat.ac.in 

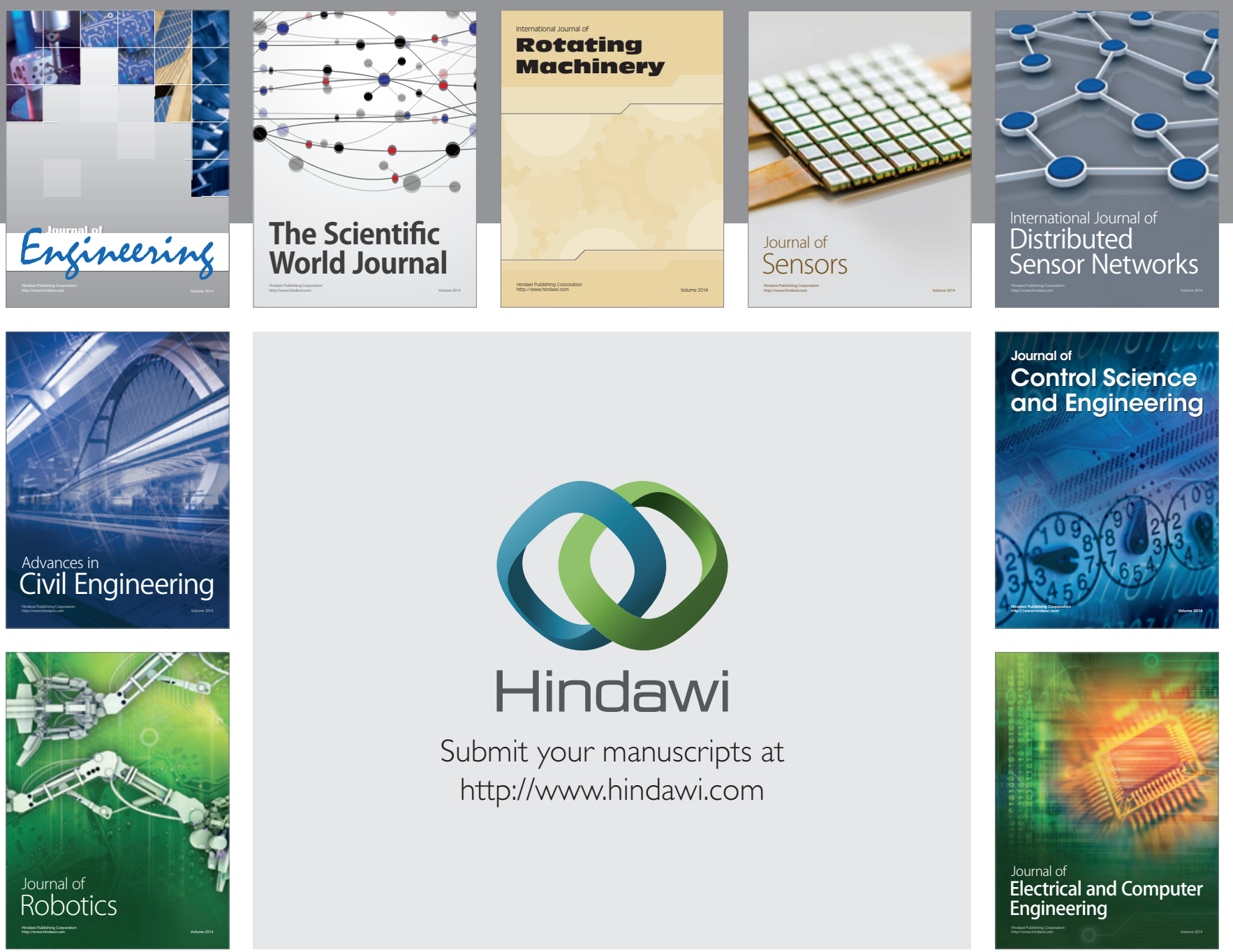

Submit your manuscripts at

http://www.hindawi.com
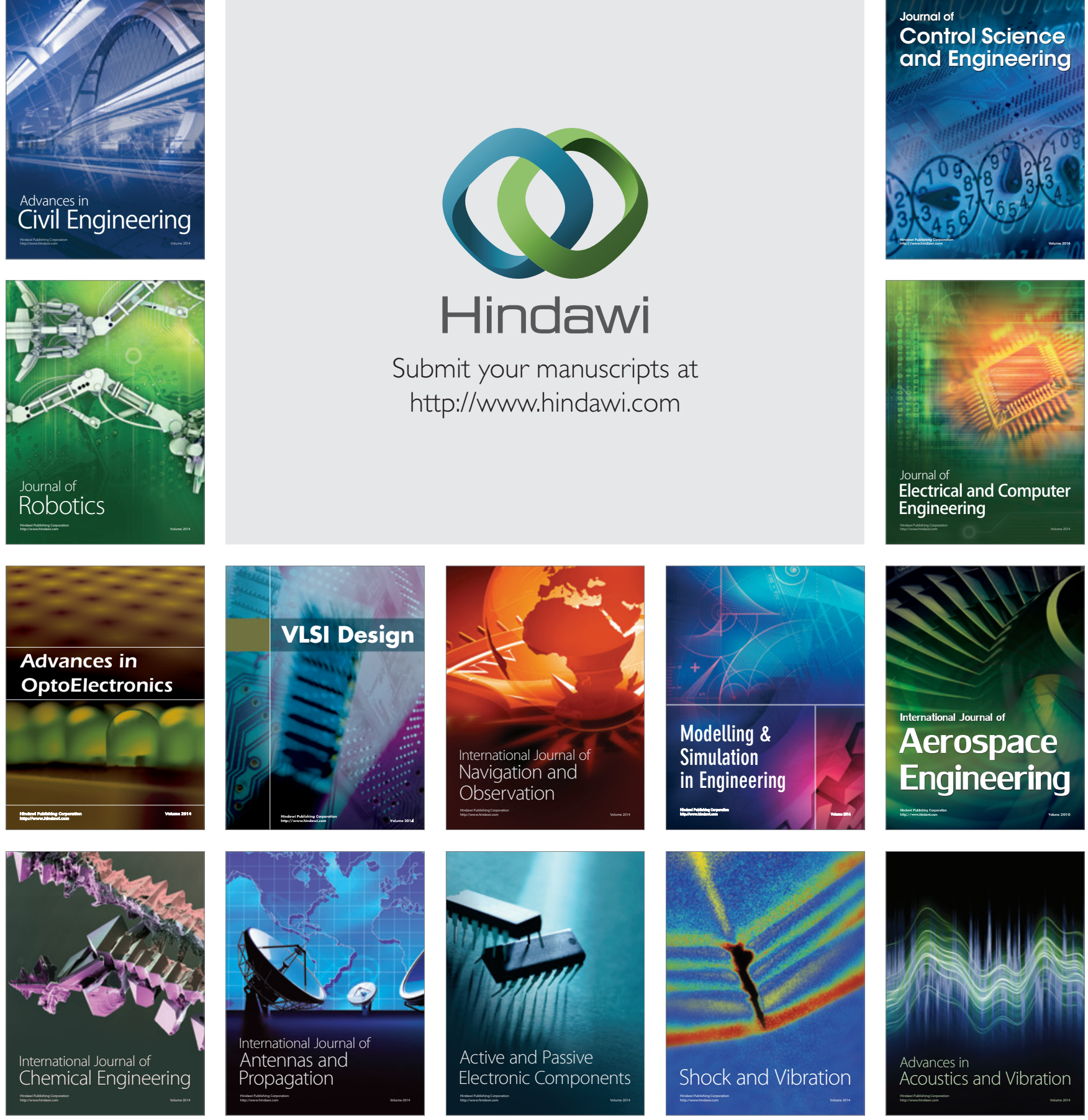